\title{
La prehistoria teatral de Rafael Alberti
}

\author{
G. TORRES Nebrera*
}

0. El 26 de febrero de 1931, ayudado por unos bocetos surrealistas de Sigfrid Burmann, se alzaba el telón profesional en el teatro madrileño de la Zarzuela para el gaditano Alberti. La crítica periodística del momento se dividió ante aquel auto sacramental sin sacramento que era El Hombre Deshabitado. El escándalo, que degeneró en manifestación política antimonárquica (en la última representación) presidió así el itinerario de Rafael Alberti como autor dramático. Itinerario que, hasta la fecha, puede jalonarse en estas etapas:

1. «Teatro Surrealista»: El Hombre Deshabitado.

2. «Teatro Epico. Teatro de Guerra»:

2.1. Fermín Galán.

2.2. Dos farsas revolucionarias (Bazar de la Providencia y Farsa de los Reyes Magos).

2.3. Primera versión de la Numancia cervantina, en pleno asedio de la capital de la nación por las tropas nacionales.

2.4. Radio Sevilla.

2.5. Cantata de los Héroes y de la Fraternidad de los Pueblos.

2.6. Un ejemplo de teatro autobiográfico en el que plantea el compromiso del intelectual ante el hecho de una revolución popular: De un momento a otro.

2.7. Noche de guerra en el Museo del Prado, la obra dramática más popularizada de Alberti dramaturgo, uno de sus mejo-

* Departamento de Literatura. Colegio Universitario de Logroño. 
res logros y el título del que se han llevado a cabo mayor número de montajes (aunque esté aún inédito en los escenarios españoles).

3. «Trilogía del exilio» (o «del terror», como definió Robert Marrast $^{1}$ a El Trébil Florido, El Adefesio y La Gallarda) : tres ejemplos de un teatro inquisidor de una España de «cales negras», en las que se bucea, por detrás de un trasfondo mítico-poético, a través del cruento choque de unas ocultas pasiones fratricidas que inciden sobre tres víctimas, unificadas en una alegorización la propia España ${ }^{2}$.

1. Pero en este paradigma del teatro albertiano queda por reseñar una primera fase (de la que me ocuparé en el presente trabajo) que no pasa de ser primeros intentos, inacabados o irrealizados (sólo proyectados) en la mayoría de los casos, y que llamo la «prehistoria teatral» de Rafael Alberti.

Dos son los únicos textos asequibles en esta fase: El Enamorado y la Muerte y La Pájara Pinta, además de las noticias de la existencia de un tercero, hasta hace poco perdido, y todavía inédito, titulado Santa Casilda ${ }^{3}$. Pero esta «prehistoria teatral» de nuestro dramaturgo, por encima de los pocos textos utilizables, es síntoma clarísimo de que su vocación escénica fue tan temprana como la poética. Que Alberti llega al teatro no por el mismo proceso de Salinas (sucesivos pasos de objetivación : poesíaprosa-teatro) ${ }^{4}$, sino por propia convicción de qué era el teatro y cómo hacerlo.

Cuando Marrast redactó su libro, tan sólo conocía el texto de La Pájara Pinta, puesto que El Enamorado y la Muerte se ha dado a conocer en fecha recientísima, y en aquel entonces, 1967, figuraba como perdido. Marrast piensa que detrás de esa serie de títulos, de los que nos han llegado noticias vagas e inciertas, sería preciso imaginar actor, escenas, persona-

1. La única monografía, sumamente breve e incompleta, hasta la fecha, sobre el teatro albertiano es la de uno de sus críticos más destacados: Robert MArRAST, Aspects du Théâtre de Rafael Alberti, S.E.D.E.S., París, 1967. En preparación tengo un volumen sobre el tema que recogerá parte de mi tesis doctoral inédita sobre «EI teatro de la generación del veintisiete: Salinas, Alberti y Altolaguirre», dirigida por la doctora María del Pilar Palomo y leida en la Universidad Complutense en octubre de 1975 .

2. No olvido incluir, en esa apretada clasificación, la adaptación prodigiosa de la famosa novela de Delicado La lozana andaluza, ni la serie de los llamados Poemas escénicos, que se dan tan de mano con los primeros intentos que situamos en esta (prehistoria dramática).

3. Tengo noticias de que existe una copia mecanográfica de este texto en poder de E. Haflter, que no he podido aún confirmar.

4. Puede consultarse el trabajo sobre el teatro de Pedro Salinas incluído en mi tesis doctoral reseñada en nota 1. 
jes, todo de una manera bastante hipotética (ya que el autor no ha conservado de ellos más que un vago recuerdo).

He aquí algunas noticias sobre esa serie de textos que, unidos a los dos que manejamos en las páginas que siguen, integrarian esa prehistoria teatral previa al primer estreno del año treinta y uno.

a) En la primera edición de Marinero en tierra se anuncia, como título en preparación por el autor, Ardiente y fría, con el subtítulo de «madrigal dramático» y, en el mismo apartado de obras teatrales, La novia del marinero.

b) «Bueno, había hecho unas pequeñas cosas; te podría dar los títulos: La novia del marinero, Ardiente y fría - comentaba el propio Alberti a su entrevistador Manuel Bayo ${ }^{5}$ - y añadia: Luego anuncié una obra que se llamaba Lepe, Lepijo y su hijo que no la hice. Otra, El hijo de la gran puta, tampoco. Todo eran proyectos, porque en ese momento yo me animé. A mí me anima el teatro cuando tengo o existe la posibilidad de estrenarlo, si no, me retraigo completamente y no lo hago»... Y continúa Alberti un poco más abajo: «No, de estas primeras, ninguna la llegué a terminar, hice fragmentos que estaban muy cerca de mis primeros libros de poesía. Se han perdido completamente. Una hermana mía que me encontró poemas muy antiguos no me encontró nada de eso y había cosas escritas, indudablemente... Ya no hice una obra completa hasta El hombre deshabitado, que coincidía exactamente con Sobre los ángeles y Sermones y moradas. Claro, el teatro que yo he hecho siempre coincide un poco con el momento poético en que estoy» ${ }^{6}$.

Marrast cree que Ardiente y fría debió ser el proyecto de una pieza dramática sobre el tema del poema que, con el mismo título, aparece en Marinero en tierra ${ }^{7}$. El crítico francés sospecha la intención posterior de Alberti de tejer sobre este cañamazo poético algunas escenas en las que los personajes reseñados cobrarían mayor vida y amplitud funcional. Incluso intenta imaginarse y reconstruir el plan de la pieza proyectada. Pero no deja de ser algo puramente hipotético que, posiblemente, ni el propio Alberti pudiera recordar, ni mucho menos corroborar ${ }^{8}$.

5. Cfr. (Alberti por Alberti), en Primer acto, núm. 150, pág. 11.

6. El subrayado de esta cita sirve para destacar un punto de referencia inexcusable a la hora de estudiar la obra dramática de estos autores del veintisiete, porque en ella se transfunde toda la cosmovisión literaria de un momento dado, constituyendo un auténtico fondo común. Alberti, por ejemplo, incrusta versos enteros de sus obras poéticas en alguna que otra producción teatral.

7. Vid. la edición de «Poesías completas» de Ed. Losada, pp. 47-48.

8. En la pág. 11 de Aspects du Théâtre... puede leerse el referido esquema. He de añadir que, según el esquema ideado por Marrast, podríamos habernos encontrado con un juego escénico que recuerda al de la primera obra teatral de García Lorca: El maleficio de la mariposa, de 1919. 
Del otro título, La novia del marinero, piensa Marrast que se trataba, o se iba a tratar, de una obra más de corte tradicional, más folklórica, Incluso, que se tratase de una primera versión de lo que después - por el año 1936- iba a llamarse Costa Sur de la muerte y acabó abriendo la «trilogía del exilio» ( $E l$ trébol florido). Pero también podría pensarse, por testimonio del propio Alberti al crítico galo («un pequeño auto a la manera de los de Gil Vicente, que fue terminado, pero que perdi también antes de la guerra») que bien pudiera ser un primer esbozo de El hombre deshabitado.

Desde luego, el tema de la novia ausente se encuentra en varios poemas de Marinero en tierra, libro con el que tuvieron mucho que ver estos primeros esbozos dramáticos ${ }^{9}$.

2. Por fin, un texto pensado y redactado totalmente para el teatro en 1930 (fecha facilitada por el propio Marrast según datos particulares de Alberti) en torno a la figura de una conocida santa hispano-árabe, que constituye el primer ejemplo más positivo de esta prehistoria teatral, pero sobre el que de momento no tenemos más que los recuerdos de su propio autor: Santa Casilda.

Haciendo una necesaria selección de tales testimonios, se debe destacar que Santa Casilda estaba «escrita en toda clase de metros y ritmos» y que Alberti la dio a conocer un mes antes de su primer estreno profesional (26 enero 1931) mediante una lectura escénica realizada por él mismo en la madrileña Residencia de Señoritas, de la calle de Miguel Angel, de la que un reseñador anónimo publicaba esta nota al día siguiente en el número correspondiente del diario «ABC»: «Rafael Alberti ofreció ayer tarde... la lectura de un poema escénico, que su autor titula Santa Casilda. Misterio en tres actos y un epílogo... Seguido con extrema simpatía por el auditorio, en el que figuraba también abundante elemento masculino, el poeta salió a la pizarra como los aspirantes a ingreso en la Academia General, y dibujó a tiza modelos sintéticos de un sintético decorado... Santa Casilda está destinada al teatro y es perfectamente representable, aunque habrá de vencer, quizá, en la escena, aquello con que suele chocar en la realidad toda producción de elevado lirismo. Su autor ha escrito tres actos, con los elementos sencillos, primitivos, claros, del romancero. Figuras del romance son el conde cautivo, el rey moro, su hija, renegada, la esclava, el coro de los soldados de Alí - uno blanco y otro negro-, el frailecillo de las barbas blancas... Las estampas se preceden con la sugestión de los tonos de oro de los retablos del siglo XV,

9. Así los poemas (Balcón del Guadarrama), «Ayer y hoy», (Sola» y «Llamada), Poesias completas, pág. 52. 
de cuya época suenan en el relato letras de canciones ingenuas y otras, transmitidas por labios infantiles de generación en generación.

Con tales temas, Alberti ha desarrollado su misterio, de un misticismo sencillísimo - primitivo, volvemos a decir_-, en el que suele respetar la construcción y las formas clásicas del romance, pero sin temer a graciosos anacronismos... El espiritu infantil, que es conducido de la mano por su autor a través de la narración poética, fue uno de los valores más tiernos y de mayor éxito de público...»

He reproducido la mayor parte de la crítica (o mejor, impresión) de urgencia del diario madrileño, porque de ella se pueden colegir -como valioso testimonio que es de un texto perdido- algunas consideraciones importantes para el resto de la «prehistoria dramática» albertiana:

a) Entronque con el Romancero. La versión escénica podría asimimilarse a un romance entre fronterizo y morisco (no en vano, cabe añadir, otra de las piezas de esta prehistoria teatral — según vamos a ver enseguida- es la escenificación de un romance novelesco).

b) No menor calidad de «romancero de ciego» tiene la versión, de ese mismo año, del tema Fermín Galán, en donde el propio Alberti introduce un pre-existente (compuesto por él mismo) «romancero» sobre el personaje jacetano que funciona como elemental cornice escénica.

c) Por lo que se puede deducir de las noticias sobre Sania Casilda y por el texto que hoy conocemos de El enamorado y la Muerte, Alberti tendió, desde el primer momento, a concebir el espectáculo totalizador, donde la música, el canto, acompaña subrayando la palabra ${ }^{10}$. Realmente, hay que reconocer que todas estas composiciones de la llamada «prehistoria teatral» albertiana surgieron del deseo de incorporar la poesía al teatro, y a partir de una imagen plástica, de la fascinante invención de un juego escénico. Aserto extensible a toda la andadura teatral del autor de La amante, comprobable para quien lea (o se atreva a montar) títulos como La Gallarda.

3. El 20 de julio de 1936 las Misiones Pedagógicas (Organo Oficial de Cultura Popular desde el año 1932) representaban en el Teatro Español

10. Recuerdos de Alberti sobre esta obra, a través de sus declaraciones a Manuel Bayo: “...lo de Santa Casilda fue una cosa un poco intermedia, un capricho extraño. Yo había estado viviendo unos días en el monasterio de Silos y allí conoci la leyenda mozárabe de Santa Casilda..., en fin, una especie de romance antiguo de moros y cristianos. Entonces hice una obra como un mural, como un fresco inspirado un poco en los capiteles y en toda la cosa legendaria de la Edad Media. Era una obra en verso muy larga, muy extensa... Está hecha con mucho conocimiento técnico de la poesía de teatro... Santa Casilda era muy pictórica, muy plástica, porque al fin y al cabo yo siempre tengo la influencia o lo que sea de mi vocación gráfica». 
de Madrid un texto "para guiñol» ${ }^{11}$ titulado $E l$ enamorado y la muerte, compuesto alrededor del año treinta, y que no es otra cosa que la escenificación de un viejo romance: la del texto que, en versión facticia, recogió Menéndez Pidal en su Flor nueva de romances viejos, y que comienza :

«Un sueño soñaba anoche, soñito del alma mía, soñaba con mis amores que en mis brazos los tenía» ${ }^{12}$.

3.1. Un simple cotejo de los textos pidalino y albertiano arroja inmediatamente las evidentes analogías textuales (o, mejor dicho, la sujeción del dramaturgo a la pauta del texto fijado por Pidal); pero también ese mismo cotejo nos ofrecería estas diferencias, desde la perspectiva del dramaturgo :

a) La inclusión, en la versión escénica, de un personaje-narrador (en el romance que incluye Pidal se inicia en primera persona, y se pasa a la tercera, casi insensiblemente, a partir del verso «muy de prisa se calzaba/más de prisa se vestía»).

b) El final de la versión dramática difiere de la romancística, evitando ese final tan trunco, y tan caro a los romances novelescos. Sin embargo, no es la prosecución que suelen darle otras versiones sanabresas y sefardies al romance, fundiéndolo con el tema del «alma penitente», que interroga al ermitaño, e incluso con la «Penitencia del Rey Don Rodrigo» ${ }^{13}$, y se reduce sólo a la constatación dramática del triunfo de la Amada-Muerte sobre la Amada-Niña. Cabe pensar desde ahora que en

11. Con esa calificación - teatro para «guiñol»— se relaciona muy mucho con la otra pieza salvada -incompleta- de este período "prehistórico»: La pájara pinta.

12. Anota D. Ramón tras el texte en cuestión: «Este curioso romance, desconocido en todas las colecciones, menos del Romancerillo de Milá, se conserva en la tradición del Noroeste de España (Asturias, León, Zamora), en Cataluña y entre los judíos espanoles de Grecia. Procede de un romance de Juan del Encina que comienza: Yo me cstaba reposando / durmiendo como solía, muy divulgado en el siglo XVI. Es una de tantas elegías amorosas. La tradición reelaboró el tema convirtiéndolo en un singular esbozo dramático de amor y muerte». Por nuestra parte cabe añadir que se acepta la muerte, como en algunos viejos lais, a la que se intenta vencer con el amor. Este fue el texto que Alberti utilizó para su versión teatral. Y constituye dentro de la historia del Romancero un ilustrativo ejemplo de lo que se ha llamado (metamorfosis romancística", de un romance trovadoresco (en su origen) a un romance novelesco. Pueden seguirse los pasos de tal evolución en el estudio de Diego Cátalán incluído en su volumen Por campos del romancero, Gredos, B.R.H., 1970, pp. 13-55.

13. Para cuanto aquí se apunta debe consultarse el citado trabajo del profesor Diego Marín, en el que se deja constancia de la enorme popularidad de este romance como primera aclaración necesaria para ese proceso de metamorfosis romancística que quiere ejemplificar, a partir de su origen en una composición trovadoresca de Encina. 
A.lberti, como buena parte de la crítica ha señalado para el teatro de Lorca - empezando por el propio Pedro Salinas - hay una dramaturgia de la muerte, un vencer a la muerte en vías de una posibilidad de amor sensual: recuérdese el hipotético final que Robert Marrast adjudica a lo que pudo ser el madrigal escénico Ardiente y fría; recuérdese, si no, la trilogía lorquiana, y muy especialmente La casa de Bernarda Alba. Factor que se contempla con todas sus posibilidades en la «Trilogía del destierro», sobre todo en $E l$ adefesio, la que tan de cerca evoca la última obra teatral que escribiera Federico.

3.2. La escenificación de este viejo romance novelesco, con la breve nómina de sus «dramatis personae» — El lector, El enamorado, la enamorada, La doncella, La muerte_ está construída sobre estas secuencias:

a) Visita intempestiva de la muerte, con el subtema de la identificación AMADA-MUERTE (constante en las diferentes versiones del romance).

b) Petición de un plazo para visitar a la amada.

c) Recuesta de amor (primer fracaso de El enamorado y fallida ayuda de La enamorada).

d) Fracaso definitivo de El enamorado, dolor de La enamorada y triunfo de la Doncella-Muerte.

3.2.1. La innovación más importante introducida por el dramaturgo en esta adaptación es la creación del personaje del LECTOR, que aparece ante el espectador según estas indicaciones: «EL LECTOR, fuera del escenario, de pie, ante un atril, abre el libro de los romances» (...) «leyendo» (...) «mientras EL LECTOR continúa el recitado»... «EL LECTOR cierra el libro de los romances» ${ }^{14}$.

Así pues, tenemos un NARRADOR-LECTOR que va «leyendo» la historia que se objetiva, que se cuenta, que se distancia en definitiva desde el escenario. Es una función dentro del espacio escénico no ajena al quehacer dramático albertiano desde sus comienzos (como vemos), antes de que el autor tuviese siquiera noticias de un segundón, por entonces, en el teatro berlinés que se llamaba Bertolt Brecht; pero lo que sí conocía Alberti ya, por aquel entonces, era lo mejor de nuestro romancero, del teatro vicentino y de buena parte de las farsas primitivas ${ }^{15}$. Efectivamente, son

14. Cfr. El enamorado y la muerte, «Revista de Occidente», núm. 128, noviembre de 1973, pág. 153-158.

15. Había leído con asiduidad y delectación a Gil Vicente y daba conferencias en La Habana (1935) sobre la presencia del más tradicional Lope de Vega en la poesía contemporánea, conferencia que ha publicado, junto con el texto de La pájara pinta, el critico Robert MarRast. 
de análoga factura a este NARRADOR-LECTOR el CIEGo y su LAZARILLo que preceden y enmarcan cada escena de Fermín Galán, el soldDADo REPUBlicano y la niña de Radio Sevilla, los personajes anciano y viUda de De un momento a otro, el enigmático BABÚ que atraviesa las secuencias dramáticas de La Gallarda y, por último, el PRólogo, escrito expresamente, y ahora sí por indicación de Brecht, para Noche de guerra en el Museo del Prado. Enlace con una de las funciones más sobresalientes del teatro épico a lo Brecht, la del distanciamiento a través de un personaje que nos «cuenta» lo que ocurre en escena, como lo haría el juglar del romance a sus receptores.

$Y$ es precisamente la parte de la adaptación dramática que corresponde a este personaje NARRADOR la que en su mayor parte es creación del propio Alberti, en la que mantiene una mímesis del «habla romanceril» muy aceptable:

EL LECTOR :

«Galán el enamorado

brazos y manos abria.

Mientras sus ansias la buscan, ella sus manos esquiva.

Al borde de la almohada una vela le encendía.

Mientras sus ansias la buscan, ella sus ansias esquiva.

Al borde de la almohada otra vela se encendía.

Al finar estas palabras, la cuarta vela encendía. Galán, el enamorado, en el lecho se tendía. Arrodillada a sus pies un canto triste le hacía ${ }^{16}$.

16. En este aspecto formal, Alberti, excepcional conocedor de las coplas y romances populares, intenta recrear el texto incluso con los clisés lingüísticos de los romances (de su habla): fórmulas deícticas (“Galán, el enamorado»), alternancias de presentes con imperfectos de irrealidad, sobre todo en boca del personaje narrador, contribuyendo asi a aumentar esa sensación de (calgo contado», distanciador, juego de marionetas, a que aludía antes. Incluso la función apelativa del narrador-juglar hacia el receptoroyente aparece en algún momento, cuando dice:

"Cuando va a subir, subir...

mirad lo que sucedia.)

subrayando el momento culminante de resolución de la dicotomía vida/muerte. 
Bastan con estas citas para comprobar que Alberti sabe plegarse casi perfectamente a la línea de una tradición poética, sobre todo formalmente, como demuestra una y cien veces en toda la serie de libros neopopularistas de su primera etapa.

Pero prosigamos el análisis.

3.2.2. Las indicaciones escenográficas, con la utilización de máscaras y vestuario, valoración ritual de la iluminación y del sonido, consiguen crear un ambiente de misterio y tristeza. La Doncella $=$ Muerte aparece con «careta y traje blanco» debajo del cual, en un momento concreto de la representación - según la iconografía tradicional- «muestra la calavera y el esqueleto»; esta Doncella = Muerte canturrea el Dies Irae a los pies del lecho donde yace el enamorado, mientras «se oyen ladridos lejanos y el siseo de las lechuzas» o doblan las campanas. Hay, pues, un inicio en estas indicaciones escenográficas de lo que Alberti (piénsese en La Gallarda) considera «teatro total». El juego de luces, sombras, sonidos que el poeta prodiga en la tercera pieza de su «trilogía del destierro» puede atisbarse aquí en varios momentos. $Y$ uno de ellos que merece subrayarse especialmente es el de la «construcción» en ballet de la secuencia inicial de la pieza: la Doncella = Muerte «va girando». alrededor del lecho donde «sueña» el enamorado,encendiendo velas en torno suyo, en medio de un jugueteo amoroso («mientras sus ansias !a buscan, / ella sus ansias esquiva. / Al borde de la almohada / otra vela le encendía») como formalización ritual del inmediato Vida/Muerte unido a la imagen representada en el dicho popular «estar entre cuatro velas».

Y a propósito de este desarrollo tradicional culto de un mismo tema: el sueño y la presencia de la muerte, que buscan romper el fino hilo de la vida, lo tenemos también reflejado en el poema de Machado (de tan hondo y sereno dramatismo) que comienza: «Una noche de verano/ - estaba abierto el balcón / y la puerta de mi casa- / la muerte en mi casa entró.», de Campos de Castilla ${ }^{17}$.

4. Al lado de lo que el propio Alberti calificó de «guirigay lírico-bufobailable» - La pájara pinta- habria que mencionar (aunque sólo sea a título de noticia) dos farsas también situadas en esta etapa primeriza, compuestas, según todos los indicios, con anterioridad a la caída de la dictadura de Primo de Rivera, por su mordaz contenido y por los datos

17. Para que nada se escape a la tradición (Alberti - ya lo hemos dicho- gusta en toda su primera etapa de saberse tradicional), en ese diálogo entre la Doncella/ Muerte y el Enamorado no faltan los juegos verbales, inicialmente conceptistas, que recuerdan la poesía de Cancionero: ardor/hielo = amor/desamor, que en definitiva no serían otra cosa que restos sintomáticos (imitados por Alberti) de ese origen trovadoresco (cortes del XV) que el romance tiene. 
facilitados por el propio autor ${ }^{18}$. Robert Marrast despacha estas dos piezas con el siguiente breve comentario: «Nous nous garderons de trop conjecturer sur ces deux oeuvres, d'ailleurs inachevées et perdues. Notons simplement que les titres sont empruntés à des formules du langage populaire: "Sabes más que Lepe, Lepijo y su hijo" signifie "en savoir plus long que les autres";"hijo de la gran puta" est un qualificatif très grossier que l'on applique volontiers comme un suprême terme de dédain ou de mépris".

En 1932 et en 1934, ces deux titres figurent parmi les oeuvres en preparation d'Alberti, dans les bibliographies données par Gerardo Diego dans ses deux grandes Anthologies. C'est donc que, à cette époque, le poète les considérait encore comme susceptibles d'être terminées et, peutêtre, publiées» ${ }^{19}$.

4.1. Si con $E l$ eñamorado y la muerte Alberti enlazaba con la línea permanente de nuestro Romancero, La pájara pinta entronca con esa otra línea dramático tradicional del paso-entremés-sainete (al menos, considerando el único acto existente de la pieza)) ya que recuerda situaciones muy semejantes (pero jamás con la riqueza de lenguaje colorista que aqui se despliega) a las de algunas piezas de Quiñones de Benavente (por citar al autor paradigma del género entremesil).

Yo creo que lo más lejano que recuerdo — declaraba Rafael Alberti a Bayo en 1970 - fue una obra que no se ha publicado hasta hace muy poco y que nunca terminé, que titulé "La pájara pinta". La hice porque apareció en Madrid una compañía de marionetas estupenda, de un italiano, Prodecca, que era magnífico... y quería llevar alguna cosa española. Entonces, un músico amigo mío, Oscar Esplá, me habló para que hiciera unas cosas exclusivamente para Podrecca... Esto era un intento de obra escrita con los pies más que con la cabeza, pero pensando en lo descoyuntado que son las marionetas» ${ }^{20}$. Estamos ante una pieza directamente enlazada con «sources de la litterature la plus elementaire, la moins élaborée, celle des comptines» ${ }^{21}$ de la que es casi imposible dar un resumen de lo que trata a lo largo de sus ocho escenas. La crítica se ha adelantado ya (el propio Marrats, por ejemplo) a señalar el posible parentesco, al menos de intención, entre esta pieza y el teatro «para marionetas» de

18. En carta a MARRAST, fechada el 23 de noviembre de 1952, dice Alberti: «Las farsas Lepe, Lepijo y su hijo y El hijo de la gran puta no se publicaron, pues no pasaron de ser un divertido proyecto de aquellos años dictatoriales (Primo de Rivera). Llegué a escribir algunas escenas ya perdidas antes de nuestra guerra» (Aspects du Théâtre, p. 22).

19. Robert MARrast, op. cit., pp. 22-23.

20. Alberti por Alberti, p. 7.7

21. Aspects du théâtre, p. 7. 
Lorca. Y ya que viene a ocasión será conveniente recordar que también Federico se hizo eco en sus versos de ese personaje de la tradición folklórico-popular de «La pájara pinta» ${ }^{22}$.

Y es que el diálogo de esta pieza se compone exclusivamente de rimas, más o menos glosadas, que los niños cantan (o cantaban) en sus corros. Como testifica Rodríguez Marín, el personaje central de «La pájara» figura localizado en el siguiente canto popular español: «Estaba la pájara pinta / sentadita en el verde limón. / M'arrodillo a los pies de mi hermana. / Con el pico recoge la hoja/con la hoja recoge la flor. / i Ay mi amor!/ ...etcétera». Y pareja procedencia tienen los que comparten la escena, «Antón Perulero», «La carbonerita» $y$ »Doña Escotofina». Alberti (como señalaba antes) ha calificado a la pieza de «guirigay» que, según Emilio Cotarelo, alude a uno de los bailes teatrales del XVII (la relación con el género entremesil y con todo el teatro menor aureo, por extensión, queda así más evidenciada), «bufo» porque se trata simple y llanamente de «unas vocalizaciones, una especie de lenguaje inventado que no necesitara traducción» y «bailable» porque - como se acaba de decir, y de acuerdo con Robert Marrast - «en effet, le dialogue est constitué uniquement de rimas que accompagnent les rondes des enfants» ${ }^{23}$.

22. Y no sólo con este título, sino que una de las piezas del teatro breve de Lorca (1928) de aire surrealista, La doncella, el marinero y el estudiante, podría relacionarse, en cierto modo, con ese madrigal dramático proyectado por Alberti, Rosa-ardiente-y-fria. En cuanto al poema en el que aparece el personaje folklórico de «la pájara», recuérdese que al comienzo del cuadro sexto de Los titeres de Cachiporra, del mismo Lorca, dice Rosita :

" ; Todo se ha perdido! ; Todo! Voy al suplicio como fue Marianita Pineda. Ella tuvo una gargantilla de hierro en sus bodas con la Muerte. $Y$ yo tendré un collar... un collar de D. Cristobalito. (Llora y canta.)

Estando una pájara pinta sentadita en el verde limón

(se atraganta) con el pico movía la hoja, con la cola movía la flor. ¡Ay! ;Ay!, ¿cuándo veré a mi amor?»

La cita se repite un poco más adelante, en la misma escena.

También Juan José Domenchina recoge el tradicional personaje en el poema «La libélula del estanque», que subtitula, además, canción infantil, publicado en el último número de Hora de España, el XXIII, noviembre de 1938, que ha dado a conocer María Zambrano, en cuya segunda estrofa se lee:

Hay la pena que cantan los niños, legendaria, como el amor, La de la pájara, pájara pinta sentadita en el verde limón.

23. Por cierto que MArRast, a lo largo de las siete páginas que dedica a este «guirigay", en su libro sobre el teatro albertiano, casi no hace otra cosa que recoger (de compiladores y folkloristas) las composiciones populares donde ya aparecen estos personajes (igual que en el prólogo a la edición del texto en el Centre de Recherches de l'Institut d'Etudes Hispaniques, en 1964). 
4.2. La estrecha relación que venimos sugiriendo entre estas primeras composiciones dramáticas con su poesía más o menos coetánea tiene ya aquí una primera comprobante: en la escena inicial de La pájara pinta se repite uno de los poemas que integran Marinero en tierra. Compruébese:

\section{MARINERO EN TIERRA}

Dondiego no tiene don, don. don.

Don dondiego

de nieve y de fuego.

Don, din, don, que no tienes don.

Abréte de noche, ciérrate de día, cuida no te corte quien te cortaría, pues no tienes don.

Don dondiego, que al sol estás ciego. Don, din, don, que no tienes don.

\section{LA PAJARA PINTA}

LA CARBONERITA.-(Llevando el ritmo con la regadora)

Don Diego que no tiene don.

$$
\text { LA PÁJARA }
$$

¡Don!

$$
\text { LA CARBONERITA }
$$

Don Diego, de nieve y de fuego, don, din, don, que no tenéis don.

$$
\text { LA PÁJARA }
$$

Abrete de noche, ciérrate de día, cuida no te corte... ${ }^{24}$

Dejando, de momento, a un lado el prodigioso juego fónico del Prólogo, analicemos el único acto redactado de esta auténtica pieza para marionetas : acto del que - intentando el resumen de contenido- diríamos que se trata de una señora casamentera — La pájara pinta- que tenía un jardín donde proporcionaba «bodas» al pueblo. Por allí desfilan, recordando la estructura del entremés de figuras, una selección de los tradicionales personajes de los cantos y juegos infantiles. Con todas las diferencias pensables, Alberti experimentaba unos años antes y con éxito presumible, de haberla finalizado, la fórmula conjugada en ancha libertad e imaginación, del teatro de marionetas, la que Lorca llevaria, por ejemplo, al Retablillo de don Cristóbal, o Valle (por cuyo teatro Alberti muestra un evidente gusto) a su «Tablado de marionetas».

Alberti, en definitiva, siempre se sitúa en la tradición, aun cuando quiere ser más vanguardista (teatralmente hablando), como ocurre con El hombre deshabitado. Por eso mismo, La pájara pinta se inscribe claramente dentro de una tradición no sólo del teatro menor, sino de la misma literatura satírico burlesca: ese desfile de figuras sancionadas por el fol-

24. La pájara pinta, ed. cit., pp. 47-48. 
klorismo y el refranero nos recuerdan, demasiado, narraciones de Quevedo como La visita de los chistes, por ejemplo. Y justamente, en la nómina de «figuras» a las que pasa revista el autor del Buscón, coincide en una con las dramatis personae albertianas, aunque sólo sea en alusión: el «don Diego de noche», aquel que, según propia confesión, «en el vestir he parecido árbol, que en el verano me he abrigado y vestido, $y$ en el invierno he andado desnudo». Este «mal cosido y peor sustentado» Don Diego de noche (con esas adjetivaciones lo pone en circulación Francisco de Quevedo) es «figura imaginada — según escribe Julio Cejador- para significar cualquier paseante embozado de los que viven de gorra, susto perpetuo de los transeúntes, como de los padres y maridos y acíbar nocturno de los saraos y bailes de candil» 25 .

5. Lo más destacable de la morfología de la pieza es que cada escena se centra, por regla general, sobre la participación de una de estas figuras, en torno a la cual «giran» (casi danzan) todas las demás. El elemento de unión muy tenue, ya que intriga dramática propiamente dicha no existe en absoluto, es que todas esas figuras vienen a confluir en casa de $L a$ pájara pinta y su criada $L a$ carbonerita para obsequiar a la primera, que viene a ser como una guiñolesca celestina.

Y la aparición de esos distintos personajes es, además, acumulativa. En cada escena se mantiene el censo anterior y se aumenta la entrada de una nueva figura folklórica o de una pareja: Antón Perulero, cortejo de «La Carbonerita» con su hermoso corazón florido en las manos ( $i$ Acaso no valgo / más que el carbonero? / Don Diego de Contreras / es mi compañero, / y en cuantito muera / Don Diego Contreras, / seré yo el primero.») y su ridícula jactancia; Don Diego Contreras y Doña Escotofina, pareja de tartamudo e histérica, rival, el primero, de Antón, a quien persigue por la escena con unas enormes tijeras - enormes como el corazón de aquél, como las cabezotas de los muñecos que asoman por ventanas y puertas - con su jugueteo fónico-repetitivo ( $\ll$ Tus narí, tus narí, / tus narí-narices,/Peru-Perulero,/por mal caballero,/don Diego, don Diego,/ don Diego Contreras/con sus sus tijeras/ti-ti-ti-tijeras-te-te cortará, $/ y$ en un pu-puchero/las las hervirá.»); la «Tía Piyaya» y «Bigotes», nuevas figuras que se acumulan a la situación anterior, que asisten el ataque de celos e histeria de «Doña Escotofina», en tanto que las escenas quinta y octava quedan interconexionadas con otra pareja de los antaños juegos infantiles, el «Conde de Cabra» y la «viudita del Conde Laurel», incorporando, en boca del corro, la estrofa tan popularizada: «La viudita, la

25. F. de Quevedo, Los sueños, ed. de Julio Cejador. Clásicos Castellanos, tomo II), p. 269 (nota). 
viudita,/la viudita se quiere casar/con el conde, conde Cabra,/conde de Cabra se le dará.»

Las dos escenas que restan para el cómputo total de las ocho que constituyen ese único acto redactado se circunscriben, una (la sexta) en torno al personaje de análoga filiación: Juan de las Viñas, y la séptima, muy breve, consagrada a la exaltación de la «Pájara pinta» «en el día de su santo» ${ }^{26}$.

6. Pero lo más importante en La pájara pinta, como constante técnica formalizadora, es la enorme potenciación musical, onomatopéyica, que adquiere el signo lingüístico. $Y$ es ese, prácticamente, el único objetivo que Rafael Alberti se propuso, porque «en ese momento yo pensaba - declara el propio Rafael - que en las óperas no se entiende nada de lo que se dice y da lo mismo escribir un texto extraordinario que no escribirlo, porque se oyen tonterías nada más o no se oye nada, sino una voz que es más o menos un instrumento de la orquesta. Entonces intenté hacer unas vocalizaciones, una especie de lenguaje inventado que no necesitase traducción» ${ }^{27}$. Alberti se refiere concretamente al prólogo, pero esa finalidad de rimas y juegos ritmicos, enormemente sonoros, son extensibles a la totalidad de esas ocho escenas.

Así se justifican exclamaciones tan enormemente sonoras (y a la vez, tan extrañas) como las de La pájara pinta, que cuando se asusta exclama repetidamente un nombre de figura geométrica (a manera de innovadora interjección) interesándole al autor únicamente por el enorme potencial sonoro de consonantes labiales y líquidas reiteradas, iniciando un jocoso trabalenguas :

\section{«iParalelepípedo! \\ ¿Paralelepípedo! \\ iParalelepípedo! \\ ¿Paralelepípedo! \\ ¡Paralelepípedo!}

o el caso del tartamudeo de don Diego puede originar efectos de este tipo, a base de un único interrogativo:

$$
\begin{aligned}
& \quad \text { ¿Qué qué } \\
& \text { qué-qué-qué } \\
& \text { qué-qué } \\
& \text { pasa aquí?» }
\end{aligned}
$$

26. La pájara pinta (ed. citada), pp. 45, 52, 58 y 79, respectivamente.

27. Alberti por Alberti, p. 9. 
Los ejemplos podrían ser múltiples, siguiendo el hilo de la lectura de toda la pieza. Conviene destacar, no obstante, que estos usos adquieren valor identificativo (marcas) ya que cada uno de los personajes repite el mismo o un par de ellos: la Carbonerita siempre exclama «iJi, ji, ji!», el chillido subrayadamente agudo de doña Escotofina, siempre aquejada de histerismo, y la expresión «paralelepípedo» alternada con

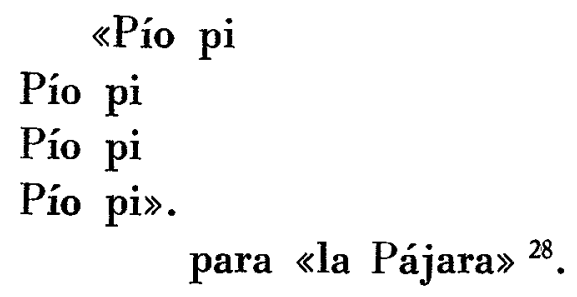

6.1. Pero donde ese lenguaje alcanza su mayor dimensión, sirviéndose no sólo de la función fática del lenguaje (según R. Jakobson) sino de la lúdica, es en el prólogo, sspléndido abanico de jitañajáforas, donde el ritmo y aliteraciones seriadas (aparte de la mejor sensibilidad fono-estilística) se alzan con la potenciación de un significante (en su forma y en su sustancia) ajeno a cualquier correspondencia de sentido lógico en el (ausente) plano de contenido ${ }^{29}$.

6.1.1. Este prólogo también tiene su anécdota: el propio Alberti lo representó en París («...yo estaba delante de la orquesta, al lado del director, porque esto no se podía decir caprichosamente. Yo tenía mis entradas con la orquesta, momentos en que ésta se callaba...»). El texto de tal representación (es decir, el «Prólogo» que nos ocupa) quedaba enmarcado en este ámbito — también evocado por el propio Alberti-: «Entonces el personaje que dirigía esa compañía popular, llamada de la Pájara pinta,

28. $\mathrm{Y}$, por último, señalaremos que este personaje citado en último lugar inicia, a veces, algunas de sus intervenciones con idénticos juegos onomatopéyicos, exentos de toda justificación a nivel de contenido.

29. Sobre la función fática del lenguaje (siguiendo a JAKoBson) y su derivación en función lúdica, ha escrito unas muy interesantes páginas Francisco Yndurain en estos dos trabajos: "Sobre la función fática del lenguaje», en Homenaje al Dr. Canellas, Universidad de Zaragoza, 1969, pp. 997-1061, en donde concluye YnduraIN sobre esta función que, «en definitiva, la función fática son los puros ademanes verbales, despojados de otra función inherente o contextual». El segundo trabajo al que hacemos referencia -y que toca más directamente el caso de La pájara pinta- es el titulado "La función lúdica del lenguaje» en el volumen Doce ensayos sobre el lenguaje, Fundación March, Madrid, 1974. Esta función - para el profesor YNDURAIN- se propone, dentro del factor del mensaje, no como una subespecie, sino como algo netamente distinto de la función poética (según dice en la pág. 218) y en la página siguiente, antes de pasar a una amplia ejemplificación de la referida función en textos muy comtemporáneos, determina que centre las funciones poéticas, digo en textos así marcados, los hay con muy poca atención para el receptor y también con una casi total carencia de función referencial, como si se prescindiera del factor correspondiente del contexto. Para estos hechos del lenguaje se propone la denominación de función lúdica) (página 220). 
también Pipirigallo -era una especie de bululú que iba por los pueblos presentando la obra o, mejor dicho, el guirigay- aparece delante del telón. Suenan unas campanillas y cascabeles, con un puntero en la mano, delante del telón, donde están pintados todos esos personajes, dice lo siguiente...» ${ }^{30}$. Y lo siguiente es este ejemplo del potencial valor fónico de la palabra y de la FUNCIón LÚdica del lenguaje (corroborando la tesis del profesor Ynduraín que hemos resumido en nota):

$\quad$ «iLadrón
landera,
deralón
dinera,
nedirlín
nedirlón
nedirlera,
ronda, rondalín, randul,
faró, faralay,
guirí, guirigay,
bul!»

(cito sólo un fragmento).

6.1.2. En cierta manera, quiere recordar la estructuración de un «villancico» zejelesco: ya que la tirada inicial (que no es la que se ha reproducido) se intercala, a la manera de un pretendido estribillo, entre las tiradas que, siguiendo la analogía terminológica, llamaríamos de glosa.

6.1.3. No puede ofrecer duda que Alberti estaba más que habituado a escuchar estos juegos verbales (especialísimos ejemplos de jitanjáforas) en las coplas y chirigotas del carnaval gaditano, durante muchos años y ocasiones. Ramón Solís, su reciente antologizador, dice que «hay, incluso, una intención de dar exotismo a las letras, cosa que se consigue con los trabalenguas disparatados de sus estribillos». Y naturalmente recoge algunas muestras de este aspecto del juego creativo de sus paisanos, que transcribo para mostrar cómo buena parte de La pájara pinta, especialmente el Prólogo, queda dentro de este «arte de trabalenguas», eso que no es otra cosa «sino que los autores de letras de canciones llaman "monstruo"», añade Solís :

«Sarapica, reberberé culi dalmática dale estopín tu repique mastrum diabólico brancatiopin le parpiné fine estrambótico tocamaitin pao pai cera...

30. Alberti por Alberti, p. 10. 
Muley faciné gazapirón travi romántica mi trovadori tuti mai zon».

(Los portamonedas, 1910) ${ }^{31}$.

7. Hasta aquí cuanto de momento puede facilitarse sobre lo que he calificado como «prehistoria teatral» de Rafael Alberti. Para completar el panorama sería necesario ( $y$ urgente) añadir a lo que se conoce el texto de Santa Casilda, ya que parece que fue el intento más serio (al menos, el único iniciado y acabado) antes de su presentación oficial con El hombre deshabitado y Fermín Galán, dos títulos que de alg’ na manera enlazan con lo entrevisto en esta «prehistoria teatral» y que aseguran, conclusivamente, que en Alberti el teatro, como la mayor parte de su lírica, son creaciones sujetas a unas líneas neo-tradicionalistas, renovadas (más que innovadas) sobre unos patrones teatrales bien delimitados, de los que Alberti cuida mucho no alejarse, y cuando intenta hacerlo (el caso de su auto sin sacramento) es sólo aparentemente, para volver de inmediato a lo que los viejos autos, Vicente, Cervantes, Lope, Calderón o los entremeses, le han enseñado. Incluso la aproximación que algún crítico ha intentado hacia Valle Inclán no es ni más ni menos que apoyar esa inscripción del Alberti dramaturgo en una tradición fehacientemente hispana.

31. Cfr. Coros y chirigotas (El carnaval de Cádiz), recopilación de Ramón Solís, ed. Taurus, pp. 7-8. 
